\title{
INCLUSÃO ESCOLAR DO ALUNO COM DEFICIÊNCIA FÍSICA
}

\section{ARTIGO ORIGINAL}

MACHADO, Carolina Dos Santos ${ }^{1}$

\section{MACHADO, Carolina Dos Santos. Inclusão escolar do aluno com deficiência} física. Revista Científica Multidisciplinar Núcleo do Conhecimento. Ano 05, Ed. 12, Vol. 19, pp. 84-97. Dezembro de 2020. ISSN: 2448-0959, Link de acesso: https://www.nucleodoconhecimento.com.br/educacao/deficiencia-fisica

\section{RESUMO}

A Educação Especial Inclusiva vai além de somente pensar, ela já está no nosso cotidiano, não sendo mais um assunto distante de nossos lares e escola. O tema inclusão está amplamente aberto para todos, o mesmo é apresentado e discutido através das mídias, e colocado em prática nos espaços escolares. Desta forma, temse como objetivo principal deste trabalho, compreender e analisar de qual forma acontece a inclusão escolar dos deficientes físicos. Esta pesquisa justifica-se pela interação e conhecimento referente a Educação Especial Inclusiva, onde esta foi criada para reconhecer, aprender e ajudar mais especificamente o aluno com necessidade especial. Cada aluno é único e tem sua essência, precisamos transmitir e receber novos saberes e experiências com eles. Como metodologia foi adotado a descritiva, com análise e levantamentos de dados bibliográficos, retirados de livros e artigos científicos. A inclusão vem ganhando espaço e quebrando paradigmas. Há algumas décadas atrás, nem existia inclusão e, ao longo do tempo isso foi mudando, cadeirantes não precisam frequentar escolas especiais ou deixar de ir à escola, porque hoje a escola está aberta a eles. A problemática desta pesquisa analisa e irá

\footnotetext{
${ }^{1}$ Pós Graduada em Educação Inclusiva pela Uniasselvi Centro Universitário Leonardo da Vinci, 2020. Pós Graduada em Atendimento Escolar Especializado pela Fael Faculdade Educacional da Lapa, ano 2020. Graduada em Pedagogia pela Uniasselvi Centro Universitário Leonardo da Vinci, 2019.
} 
descrever um pouco do mundo de um aluno cadeirante, onde o mesmo já possui alguns de seus direitos garantidos por lei, como acesso livre em quase todos os lugares, por isso, quais formas e como funciona esse acesso livre aos cadeirantes atualmente? Por fim, pode-se concluir que as escolas estão se adaptando conforme a necessidade especial e assim, facilitando o acesso para o aluno. A sociedade em um todo está se preparando mais para esse momento permanente e a escola se preparando mais ainda.

Palavras-chave: Aluno, inclusão, cadeirante.

\section{INTRODUÇÃO}

A Educação Especial vem de um longo caminho com muitas lutas e fases para obter as mudanças e evoluções significativas na história da educação, e começamos pelo nome que era chamado de deficiência passou a ser chamado de condição especial. A Educação Especial nos faz refletir mais sobre o 'outro', e refletir sobre os valores morais e éticos em cada época.

A pessoa com uma necessidade diferente era chamada de deficiente na época, à mesma era excluída da sociedade, ficando em casa com seus familiares, sendo escondido da sociedade ou até mesmo eram abandonados, os mesmos eram citados como contaminantes, ou seja, que poderia contaminar o restante da população era também associado a eles maldições. Ao decorrer dos anos essa ideia foi sendo modificada através da expansão do cristianismo, tendo uma visão pressuposta de que seria uma pessoa dotada de alma e necessitaria ser socorrido pela sociedade.

A aceitação nos traz aos poucos uma nova fase que foi chamada de "segregação" que seria uma separação do indivíduo da sociedade, elas eram levadas para um lugar chamado de escola especial ou instituições residências segregado que ficava longe da cidade e de suas famílias, assim recebendo algum aprendizado.

Foi na época do século XIX que o ambiente escolar passou a ser ter um fundamental papel para os indivíduos com necessidades especiais, mas lembrando que ainda 
estavam excluídas ou segregadas da sociedade, nesse momento seria a primeira vez que recebiam uma parte da educação. Glat (1998, p. 11) nos explica que.

Tradicionalmente o atendimento aos portadores de deficiência era realizado de natureza custodial e assistencialista. Baseado em um modelo médico, a deficiência ara vista como uma doença crônica e o deficiente como um ser inválido e incapaz, que pouco poderia contribuir para a sociedade, devendo ficar aos cuidados das famílias ou internados em instituições 'protegidas', segregadas do resto da população.

Beyer (2005, p.15) relata e adverte que, "as escolas especiais foram importantes historicamente, mas uma solução transitória não tem ou não deve ter caráter permanente", precisamos ter a consciência da importância dessa faze para a história, e que esse foi um meio de receber algum tipo de educação. Com essa fase veio também a "institucionalização da deficiência" que tem o significado de ofertar algum ensino para as pessoas com deficiência em ambiente fora da escola regular e do convívio social ou escola separada.

Em 1970 veio a "desinstitucionalização" e com ela veio algumas mudanças socioeducativas como incluir e integrar gradualmente as pessoas com deficiência na escola regular. Também tem a fase da "integração" é a inclusão do deficiente na escola regular, mas em grupos separados do restante, sendo assim só para dizer que o mesmo está incluso.

E por fim temos a fase da "inclusão", onde os alunos com necessidades especiais são incluídos ou inseridos na escola e no mesmo grupo de pessoas "ditas" normais.

Ao longo do trabalho vou explanar um pouco sobre a inclusão especial de um cadeirante, falarei sobre algumas dinâmicas pedagógicas, estratégias, e como pode ocorrer no decorrer de sua vida estudantil. Segundo BRASIL, MEC/SEESP, (1994, p.17).

[...] um processo que visa a promover o desenvolvimento das potencialidades de pessoas portadoras de deficiências, condutas típicas ou altas habilidades, e que abrange os diferentes níveis e graus do sistema de ensino. Fundamenta-se em referenciais teóricos e práticos compatíveis com as necessidades específicas de seu alunado. 
processo deve ser integral, fluindo desde a estimulação essencial até os graus superiores de ensino. Sob esse enfoque sistêmico, a educação especial integra o sistema educacional vigente, identificando-se com sua finalidade, que é a de formar cidadãos conscientes e participativos.

Neste seguinte segmento, irei me aprofundar mais nos estudos sobre a inclusão escolar dos deficientes físicos, onde obtive experiência direta no meu estágio no decorrer do curso, caracterizando as dificuldades e possibilidades da inclusão sobre as leis que os ampara e a sua convivência na sociedade, onde no mundo em que vivemos atualmente essas pessoas estão amparadas pela lei, tendo assim uma melhor qualidade de vida, e convivendo em harmonia com as outras pessoas da sociedade atual, tendo os seus direitos garantidos na sociedade.

O assunto é interessante, pois a cada dia em sala de aula será um novo desafio, tanto para o aluno especial, educador, e escola, todos precisamos dar o melhor de nós a eles, pois é na escola que está uma chance de uma melhor condição e de vida, também se estendendo a sua família essa melhoria, eles são capazes de fazer ou realizar o que desejam pode demora mais tempo, mas isso não os impede.

\section{O DIREITO A EDUCAÇÃO NA ERA DA INCLUSÃO}

A garantia legal para a inclusão é um fato recente, até pouco tempo atrás os sujeitos com deficiência eram mantidos a parte da sociedade, ficavam isolados em suas casas convivendo com poucos familiares. algumas famílias não se contentavam em deixar seus filhos deficientes fora do convívio social e empreenderam uma luta pela efetivação dos direitos de todos serem cidadãos. Inúmeros são os filmes e livros que ilustram esta luta em benefício de uma aprendizagem inclusiva destes educandos.

A partir disso, alguns setores da sociedade comeram a mobilizar- se em favor da mudança de atitude em relação aos deficientes. Muitos foram às discussões que levaram a termos de leis nos dias de hoje.

A educação é um direito garantido a todo cidadão brasileiro, na Constituição Federal, no artigo 205 está declarado que a educação é um direito de todos e um dever do Estado e da família, sendo que é também um compromisso da sociedade e que esta 
deve colaborar com o desenvolvimento da pessoa, seu preparo para a cidadania e sua qualificação para o trabalho. No entanto, algumas pessoas não têm acesso a este direito fundamental, mesmo com a garantia legal para isso. Em particular, neste trabalho, estaremos falando de crianças e adolescentes com algum tipo de deficiência.

A preocupação com o tema surgiu a partir de uma experiência vivenciada, vendo a dificuldade de uma mãe para conseguir vaga em uma escola para sua filha que apresentava um comprometimento na aprendizagem, foi possível notar que as escolas precisam repensar sobre seus paradigmas de educação para melhor compreenderem sua função social.

Esta mãe teve que buscar na justiça o direito para que sua filha fosse aceita na Escola de Educação Infantil (creche). Só assim teve o direito de sua filha garantido, podendo então matriculá-la na escola, já que sua deficiência não a faz menos cidadã que as outras crianças. Agora a menina está na escola e tem uma professora e tem uma professora específica para acompanhá-la de perto.

Como consequência desse investimento vem progredindo cada dia mais e tendo uma grande ajuda de seus colegas que a tratam muito bem e também a cuidam, vendo a felicidade desta criança percebo que todas devem ter os mesmos direitos. Este pequeno relato demonstra uma face da inclusão de crianças e adolescentes com deficiência.

Os aspectos legais existem e são utilizados por quem os conhece, porém, além da parte legal, é preciso considerar também os aspectos que dizem respeito à aprendizagem destes sujeitos e como estarem integrados com os demais, ou seja, a verdadeira inclusão escolar.

A convenção sobre os Direitos das Pessoas com deficiência foi assinada em Nova lorque, em 30/03/2007, e foi ratificada pelo Brasil com o Decreto Legislativo no 186/2008, Decreto Executivo oㅜ 6.949/2009 (no Congresso Nacional, por ter recebido três quintos dos votos dos membros da câmara e senado, em dois turnos (quórum qualificado), passou a ter prestígio de uma norma constitucional). 
Para o atendimento ideal desses parâmetros as escolas devem definir formas inclusivas de atendimento de seus estudantes, cabe ao sistema de ensino oferecer o apoio necessário para a implantação de salas com recursos multifuncionais, a formação continua dos educadores para atendimento educacional especializado, a formação de gestores, educadores e os demais profissionais da escola para o aprendizado inclusivo e adequação arquitetônica dos ambientes escolares, elaboração, produção e distribuição de recursos para a acessibilidade dos alunos especiais, bem como a estruturação de núcleos de acesso a visitas e a implantação e a acomodação da diferentes ações institucionais de inclusão de maneira que ofereça condições para o crescimento acadêmico dos alunos, proporcionando sua plena e efetiva participação na sociedade.

A participação da sociedade em geral desenvolvendo uma inclusão globalizada e de fácil acessibilidade para todos. Com a falta de conhecimento e de experiências concretas de inclusão e a sensação de obrigação compulsória das autoridades e não dependêssemos da movimentação dos professores poderia acontecer de nunca haver uma mudança de direção no quesito da inclusão. Nesta linha de pensamento de estudo dessa matéria da maneira diferenciada do que ficou classificado, não alcança só as pessoas com deficiência ou necessidades especiais.

Na declaração de Salamanca abaixo descrito, define que a inclusão engloba, também, os indivíduos, que, de alguma forma e motivo, estão sendo deixado de fora das escolas regulares de ensino. Salamanca (1994).

... escolas deveriam acomodar todas as crianças, independentemente de suas condições físicas, intelectuais, sociais, emocionais, linguísticas e outras... incluir crianças deficientes e superdotadas, crianças de rua e que trabalham, crianças de origem remota ou de população nômade, crianças pertencentes a minorias linguísticas, étnicas ou culturais, e crianças de outros grupos desvantajoso ou marginalizados.

A inclusão predispõe aos que são separados pela imperfeição, pela classe social ou pela raça, tem o seu direito garantido de ter sua inserção na sociedade, sabendo que caso isso não ocorra essas pessoas serão sempre oprimidos e terão uma vida social 
incompleta, hoje em dia todo mundo tem seu lugar na sociedade, e é assegurada ao professor que a maior vitória é garantir a todos o direito a educação.

O grupo de funcionários da escola inclusiva está responsável em discutir o motivo de das reprovações nos estudos e insubordinação, sabendo que a inclusão vai mais além de rampas e banheiros adaptados, os professores tem que se aprimorar para poder oferecer resultados e a presença dos pais no ambiente escolar, dando liberdade para os educandos entender de acordo o seu tempo e condições físicas e cognitivas, cada educando tem o seu próprio tempo, onde deve ser respeitado dentro e fora da sala de aula. Muitas pessoas ainda acreditam que o melhor é separar os alunos com deficiência dos outros, mantendo em escolas especiais onde o ensino é elaborado com adaptação para tal, nos tempos de hoje temos avanço, onde todo mundo tem consciência de que é um direito de todos irem para a escola regular.

Estamos em uma era de consciencialização, todos por um propósito, fazer com que esses alunos tenham as mesmas chances que todos os outros colegas de sala de aula ou até mesmo fora dela, onde a vida segue de uma maneira diferente de uma sala de aula, acredito que fora ela tem mais dificuldades, pois tudo a sua volta está ainda em constantes mudanças para melhorar a vida dos portadores de deficiência física.

O objetivo da educação inclusiva é inserir os alunos nestas condições físicas no mesmo ambiente de ensino dos demais sendo visto do meu ponto de pensamento, como uma educação mais globalizada e estruturas que se torne possível para nós professores conseguir prosseguir com conteúdo lúdico sem maiores problemas, proporcionando ao aluno o bem-estar em sala de aula. A partir deste contexto a inclusão escolar tem suscitado muitos debates entre profissionais tanto na área de educação, como na saúde, mostrando como um grande desafia a nossa comunidade escolar, a família e aos serviços de saúde, no que se trata de educação infantil, se destaca vários fatores como se dá a permanência e a qualidade de ensino em nosso ambiente escolar. De acordo com o autor Romeu Kazumi Sassaki (2003, p.15): 
Educação inclusiva como sendo um conjunto de princípios e procedimentos implementados pelos sistemas de ensino para adequar a realidade das escolas à realidade do alunado que, por sua vez, deve representar toda a diversidade humana. Nenhum tipo de aluno poderá ser rejeitado pelas escolas. As escolas passam a ser chamadas inclusivas no momento em que decidem aprender com os alunos o que deve ser eliminado, modificado, substituído ou acrescentado nas seis áreas de acessibilidade, a fim de que cada aluno possa aprender pelo seu estilo de aprendizagem e com o uso de todas as suas múltiplas inteligências.

A formação ou preparação do profissional da educação, nesse contexto refere-se as bases nas novas realidades e exigências contemporâneas, segundo Sage (1999) analisa a relação entre o gestor escolar e a educação inclusiva, reconhece que a prática dessa educação requer alterações importantes nos sistemas de ensino e nas escolas.

Dentre esses fatores podemos citar os aspectos administrativos, organizacionais, do espaço físico, de rotinas, de práticas da instituição e os processos de formação dos educadores em si. Em nosso ambiente de trabalho onde convivo todos os dias com estes tipos de situação é necessário abordar que não somente transmitimos o saber, mas também oferecemos cuidados a estas crianças, que fica marcado pelo desenvolvimento de aquisições linguísticas, atitudinais, afetivas, sociais, e psicomotoras, em que as crianças interagem com muito mais liberdade, sem se preocupar em ter um currículo de tarefas a cumprir.

Em nossa ação de cuidar, consideramos principalmente a necessidade de cada criança cuidando em que possam ser ouvidas e respeitadas podendo dar pistas importantes sobre a qualidade do que estão recebendo, seguindo sempre os procedimentos de cuidado e promoção a saúde, atingindo assim os objetivos dos cuidados e preservação da vida e com o desenvolvimento das capacidades humanas é necessário que estas atitudes sejam cabíveis a nós professores em sala de aula, agregando assim os conhecimentos biológicos, emocional e intelectual de cada criança que ali cuidamos e ensinamos diariamente. 
É necessário que nós professores ficamos atentos a essas necessidades particulares da criança com deficiência física, procurando promover um espaço seguro e confortável diante da atuação pedagógica, porém a falta de conhecimentos específicos quanto aos cuidados que se precisa ter com estas crianças, traz ao professor muitas preocupações relacionadas à sua atuação diante do aluno com deficiência física no cotidiano escolar, porque estas professoras se sente responsável por seus alunos naquele período de tempo em que fica na escola, e se esta atuação se realizar de forma adequada pode ajudar e muito na evolução do quadro do aluno.

\subsection{UM OLHAR PARA A HISTORICIDADE DA INCLUSÃO}

O tema deficiência tem muitas interpretações equivocadas, passa por caracterizações do senso comum, que até se utiliza de termos pejorativos para defini-lo. Não é raro ouvir-se que "aquela criança é retardada, o que aprender será lucro, não quero meu filho junto com este deficiente porque ele vai pegar os 'tiques' do outro".

Há alguns recortes do assunto que se tornam regras gerais e são cultivados por boa parte da sociedade. Então, para que seja possível contribuir com a inclusão é preciso conhecer o que pontuam importantes documentos a esse respeito. Deficiência, segundo a Convenção da Guatemala, "é uma restrição física, mental ou sensorial, de natureza permanente ou transitória, que limita a capacidade de exercer uma ou mais atividades essenciais da vida diária, causada ou agravada pelo ambiente econômico e social" Gil, (2005, p. 17):

A Convenção Interamericana com propósito de eliminação das diversas as formas de discriminação contra pessoas portadoras de deficiência, de 28 de maio de 1999.

De acordo com o Parecer ํo. 02/2001 do Conselho Nacional de Educação/Câmara de Educação Básica, (CNE/CEB) os alunos que apresentam necessidades educacionais especiais são aqueles que demonstram, durante o processo educacional, claras dificuldades de aprendizagem ou limitação no processo de desenvolvimento. Estas características dificultariam o acompanhamento das atividades curriculares, pois 
possuem limitações vinculadas a causas orgânicas específicas ou relacionadas às condições, disfunções, limitações e/ou deficiências.

É ainda consideravelmente pequena a presença de crianças e adolescentes com alguma deficiência em escolas regulares, o Instituto Brasileiro de Geografia e Estatística (IBGE, 2007) afirmam que há seis milhões de crianças e adolescentes portadores de algum tipo de deficiência. Todavia, segundo o Instituto Nacional de Pesquisas Educacionais (Inep), desse total, apenas 80 mil estão inseridas no ambiente escolar.

A Instituição escolar de qualquer nível, principalmente da educação básica, deveria cumprir seu papel como sendo um espaço sócio cultural em que as mais diferentes realidades se cruzam e, portanto, um espaço privilegiado de cidadania, mas, no entanto, precisa ter condições para isso. O problema então está no indivíduo, neste contexto passa a ser usada a concepção de classificação dos alunos, como bons, médios e fracassados.

Historicamente, para quem não se enquadrava no critério normalidade, foram criadas classes especiais, ou seja, um espaço para aqueles alunos que apresentassem um grau de deficiência, que permitisse ser educável, já que não conseguiram satisfatoriamente ser atendidos em classes escolares comuns. Uma das formas de encaminhamento de uma criança que estudava em uma classe regular era transferida para uma classe especial que começava com a suspeita da professora de classe, onde era preenchida uma ficha questionário onde depois era encaminhando para avaliação, desenvolvendo o relatório com o encaminhamento para a classe especial.

Não havendo um serviço especializado para isto, muitas vezes o encaminhamento acabava sendo feito pela diretora da escola ou até mesmo pela própria professora da criança, sendo que não são profissionais especializados para isso. Um motivo, para uma criança ser apontada pelo professor para avaliação de especialistas, era sua permanência pelo menos dois anos na mesma série/ano ou suas sucessivas reprovações. 
Na contemporaneidade se torna necessário encaminhar uma criança no início de suas atividades escolares desde que os professores ou a família suspeite de que algo está comprometendo seu desenvolvimento escolar ou sócio afetivo e na convivência social. Muitas vezes a ida de um aluno para a classe especial era tida como um alívio para o professor que não sabia como lidar com a situação que se apresentava por ter pouca ou nenhuma orientação para trabalhar com este aluno. A falta de conhecimento sobre o assunto podia fazer $\mathrm{cm}$ que o professor confundisse deficiência mental com problemas de comportamento e/ou aprendizagem.

Algumas crianças vistas como deficientes mentais, apenas sofrem ou sofreram algum problema de ordem externa: familiar, emocional ou mesmo escolar. Outras vezes, o atraso, se é que ele existe, está ligado às condições culturais da criança, onde encontra-se excluída do contexto das relações sociais em que à favoreça no seu desenvolvimento, ou ser negligenciada pelas pessoas que estão ao seu redor.

Com o passar dos anos e avanços dos estudos na área, pode-se notar que crianças antes descobertas como deficientes, hoje não são mais consideradas assim, atualmente existe muitos exames comprobatórios que diagnosticam as crianças com profissionais capacitados para isso, o diagnóstico precisa ser feito por uma equipe multidisciplinar, geralmente é composta por pediatras, neurologistas, fonoaudiólogos, psicólogos, psicopedagogos e fisioterapeutas. Outros profissionais podem se fizer necessário a uma avaliação. O tipo de problema apresentado é que vai determinar as áreas a serem avaliadas, é essa equipe que pode então, diagnosticar se a criança ou o adolescente é portador de alguma deficiência ou não.

O direito à educação é, ao mesmo tempo, um direito humano e fundamental. Teve esse reconhecimento na Declaração Universal de Direitos Humanos (1948, art.26) e também no Pacto Internacional de Direitos Econômicos, Sociais e Culturais (PIDESC, 1966, p.09). 


\subsubsection{A INCLUSÃO ESCOLAR DE ALUNOS COM DEFICIÊNCIA FÍSICA}

A inclusão deve sair do ambiente escolar e se expandir, ir além, ir para as ruas e entrar em suas casas. Historicamente, as pessoas com deficiência eram definidas por vários paradigmas no decorrer da história humana, onde os quais resistiram ao longo dos séculos, provocando consequências históricas, porque se torna mais fácil prestar atenção aos impedimentos, e as aparências do que nos potenciais e capacidades das pessoas. Um importante conceito sobre a Educação Inclusiva é afirmado pelo autor Mantoan (2004, p.45):

é fruto de uma educação plural, democrática e transgressora, haja vista que a mesma gera uma crise escolar, ou seja, uma crise de identidade institucional, que, por sua vez, abala a identidade dos professores e faz com que seja redefinida a identidade do aluno. Deste modo, a educação para todos tem como objetivo desempenhar seu dever de abranger todas as crianças na escola e defender valores éticos, justiça e direito de acesso ao saber e à formação.

A aptidão das pessoas, desde o princípio, sempre reprovou os portadores de deficiência física, isolando e abstendo de sua liberdade, esses indivíduos sempre foram alvo de atitudes preconceituosas e ações impiedosas. Na contemporaneidade o que se percebe é que mesmo com avanços significativos no que se referem a questões sociais, políticas e legais as pessoas que são portadoras de deficiência física ainda continuam à margem da sociedade, sendo vítimas de preconceito e são consideradas como incapazes e improdutivos chamados por nomes desonrosos como: coitados, pobrezinhos e outros.

$\mathrm{Na}$ vida real, o processo de inclusão vai muito além da inserção dos alunos com deficiência na escola dita regular ou na reserva de um percentual de vagas em concursos públicos a serem ocupadas por candidatos com deficiência, na visão geral é necessário que seja feita uma mudança na estrutura social vigorante, no sentido de organização de um sociedade que entenda e atenda os interesses de todas as pessoas sem descriminação, neste sentido lutando por uma inclusão social de responsabilidade global. 
A deficiência física é caracterizada por características degenerativa como no caso de distrofias musculares e tumores que afetam o sistema nervoso, nos casos não evolutivos, conforme o sujeito recebe estímulos facilitadores de seu cotidiano suas limitações tendem a ser menos graves por motivos de práticas e adaptações a cada ambiente. No caso evolutivo os problemas da saúde do indivíduo se agravam, e os desafios encontrados em seu cotidiano, acabam sendo cada vez mais desconcertantes.

A escola tem que proporcionar um ambiente agradável, seguro, confortável e estimulante, onde os alunos tenham condições de aprender, e se desenvolver superando seus medos e desafios que venham encontrar na sua rotina diária, ajudando a encontrar meios facilitadores de ensino e aprendizagem e formas de livre locomoção dentro do ambiente escolar, ainda existem muitas barreiras para um ensino de qualidade para estes alunos no ambiente escolar, devendo a escola estão preparadas para atender todos eles, oferecendo oportunidades para que o aluno possa desenvolver suas habilidades, ser respeitadas e ter direitos e deveres iguais a todos os alunos da instituição escolar.

A política Nacional de Educação Especial na Perspectiva da Educação Inclusiva (2008) se remete para os processos de inclusão escolar em todos os períodos da Educação Básica, que se estende da Educação infantil até o Ensino Superior.

É importante adequar materiais e garantir a inclusão em todos os níveis de ensino, através do trabalho colaborativo entre a equipe pedagógica, o professor, os alunos e a comunidade escolar. Além das adaptações a instituição também deverá ser adaptada em sua estrutura física, construindo rampas de acesso a todos os ambientes, nos banheiros, as portas que permitam a entrada de cadeiras de roda, corrimões, pisos e tapetes antiderrapantes, mobílias e cantos arredondados, além de todas as mudanças no geral para melhor atender as necessidades dos estudantes com deficiência física, são necessários ressaltar que o recurso material sozinhos não assegura a participação e inclusão dos alunos, precisa ter uma interação social para tornar-se uma inclusão com significado real. 
Além de tudo o convívio com os amigos que as crianças ampliam a probabilidade de aprenderem juntas, no brincar essas probabilidades aumentam. É importante ressaltar que a criança com deficiência física pode apresentar mais alguma outra deficiência agregada podendo ser intelectual ou sensorial, provocando necessidades diferentes, para esses diferenciais o professor tem que estar preparado tanto psicologicamente como profissionalmente para elaborar um bom trabalho.

Em sala de aula é necessário entender e discutir e ter objetivos no processo de inclusão porque cada aluno é singular em minha experiência vivida em sala de aula com alunos com deficiência no sistema público de ensino brasileiro se revela muito seletiva, embora estejam alegando que é democrática, sendo classificatória e estigmatizante que contribui para a reprodução de ordem estabelecida e para a legitimação das desigualdades entre os agentes escolares o que contribui o processo de exclusão por dentro do sistema escolar. É necessário que tenha alternativa justa no sistema escolar para compensar suas limitações e se capitalizarem para enfrentar uma sala de aula inclusiva e humanizada com direitos iguais para todos, aprendendo com o que está diferente do currículo do ensino comum e se tornando necessário para que possam ultrapassar as barreiras impostas pela deficiência.

\section{CONSIDERAÇÕES FINAIS}

Tendo em vista concluo que os tempos são modernos e as pessoas estão incluindo mais os portadores de alguma necessidade especial, ainda a um longo e árduo caminho a se expandir e percorrer, somos uma sociedade desunida, ainda dependemos de leis para garantir o mínimo de direitos para os mesmos.

No presente contexto a realidade dos educadores é de insegurança e despreparo, pois o curso de qualificação ainda é de alto valor, e a demanda de professores são poucas e muitas escolas ainda não está nos padrões de acessibilidade para o aluno especial, falta material adequado na escola regular. 
Muitas vezes o educador usa métodos tradicionais, sendo que precisamos de novos métodos eficazes, mas não estamos parados no tempo não, houve um avanço muito significativo ao longo dos anos, algumas fases foram citadas ao longo desse trabalho.

De uma maneira geral observei com a convivência próxima a um aluno com deficiência física, que devemos estar sempre nos atualizando adquirindo conhecimentos específicos com formação continuada, como também está atualizado com os profissionais de saúde que acompanha esta criança, tendo uma comunicação estreita para poder oferecer um atendimento melhor em caos de emergência, como por exemplo, saber acalmar as outras crianças em uma hora de pânico e cuidar a criança com deficiência física em um caso de convulsão. Oferecendo a devida assistência sem correr riscos de ocorrer sequelas a esta criança, tornando- se necessário um ensino globalizado e humanizado em todas as escolas.

\section{REFERÊNCIAS}

BEYER, Hugo Otto. Inclusão e avaliação na escola: de alunos com necessidades educacionais especiais. Porto Alegre: Mediação, 2005. p.15.

BRASIL, Ministério da Educação e do Desporto. Política Nacional de Educação Especial. Brasília, MEC/SEESP, 1994.p. 17.

BRASIL. Ministério da Educação Diretriz Curriculares Nacional da Educação Básica, Secretaria de educação Básica/Secretaria de Educação continuada, Alfabetização, Diversidade e Inclusão, Secretaria de educação profissional e Tecnológica. Conselho Nacional da Educação. Câmara Nacional de Educação Básica. Diretrizes Curriculares Nacionais Gerais da Educação BásicalMinistério da educação. Secretaria de educação Básica. Diretoria de Currículos e Educação integral. Brasília: MEC, |SEB, DICEI,2013. p.562. ISBN:978-857783-136-4-2013.

\section{DECLARAÇÃo DE SALAMANCA: Princípios, Política e Prática em Educação}

Especial. 11994. Disponível em: WWW.direitoshumanos.usp.br Acesso em: out. 2019. 
GIL, Marta (Coord.). Educação Inclusiva: O que o professor tem a ver com isso? São Paulo: Imprensa Oficial do Estado de São Paulo, 2005.p.17.

GLAT, Rosana. A integração social dos portadores de deficiência: uma reflexão. Rio de Janeiro: Sette Letras, 1998. p.11.

MANTOAN, M.T. E. Igualdade e diferenças na escola: como andar no fio da navalha. In: ARANTES, V.A. Inclusão escolar: pontos e contrapontos. São Paulo: Summus, 2006.

SAGE, Daniel D. Estratégias administrativas para a realização do ensino inclusivo. Porto Alegre RS: 1999.

SASSAKI, R.K. Vida Independente: história, movimento, liderança, conceito, filosofia e fundamentos. São Paulo: RNR, 2003.

Enviado: Novembro, 2020.

Aprovado: Dezembro, 2020. 